\title{
Contribution of Next-Generation Sequencing to Aquatic and Fish Virology
}

\author{
Andriniaina Andy Nkili-Meyong ${ }^{a}$ Laurent Bigarréb ${ }^{\text {Ingrid Labouba }}{ }^{a}$ \\ Tatiana Vallaeys ${ }^{c}$ Jean-Christophe Avarre ${ }^{d}$ Nicolas Berthet ${ }^{a, e}, f$ \\ ${ }^{a}$ Département Zoonoses et Maladies Emergentes, Centre International de Recherches Médicales de Franceville \\ (CIRMF), Franceville, Gabon; b ANSES, Laboratoire de Ploufragan-Plouzané, Université Bretagne-Loire, Plouzané, \\ 'Université de Montpellier and ' ISEM, IRD, CNRS, Université de Montpellier, EPHE, Montpellier, and \\ ${ }^{e}$ Centre National de Recherche Scientifique (CNRS), UMR3569, and ${ }^{f}$ Cellule d'Intervention Biologique \\ d'Urgence, Unité Environnement et risques infectieux, Institut Pasteur, Paris, France
}

\section{Keywords}

Viruses · Fish · Diagnostics · Next-generation sequencing · Aquatic virology

\section{Abstract}

The recent technological advances in nucleic acid sequencing, called next-generation sequencing (NGS), have revolutionized the field of genomics and have also influenced viral research. Aquatic viruses, and especially those infecting fish, have also greatly benefited from NGS technologies, which provide a huge amount of molecular information at a low cost in a relatively short period of time. Here, we review the use of the current high-throughput sequencing platforms with a special focus on the associated challenges (regarding sample preparation and bioinformatics) in their applications to the field of aquatic virology, especially for: (i) discovering novel viruses that may be associated with fish mortalities, (ii) elucidating the mechanisms of pathogenesis, and finally (iii) studying the molecular epidemiology of these pathogens.

(c) 2017 S. Karger AG, Basel
\end{abstract}

J.-C.A. and N.B. contributed equally to this work. (c) 2017 S. Karger AG, Basel

\section{Introduction}

The first clue that aquatic viruses play a major role in their environment came from investigations in the early 1990 s that revealed their high abundance $[1,2]$. For example, viruses are the most abundant organisms in the marine environment [3]. It was estimated that each milliliter of seawater contained millions of viral particles [4] and that viral particles accounted for about $94 \%$ of nucleic acid-containing particles $[5,6]$. Some environmental studies on aquatic viral communities have shown that the "unknown fraction" (i.e., without homology to any sequence available in the databases) is substantial, and may range from 30 to $99 \%[7,8]$. A recent study focusing on the analysis of virus open reading frames (ORFs) showed that a large fraction had no homologs in databases. These "ORFans" are more frequently present in viruses than in bacteria (respectively 30 and 9\%), suggesting that the diversity among viruses may be even greater than suspected [9].

Dr. Jean-Christophe Avarre

Institut des Sciences de l'Evolution de Montpellier

UMR 226 IRD-CNRS-UM-EPHE, Place Eugène Bataillon

FR-34095 Montpellier (France)

E-Mail jean-christophe.avarre@ird.fr

\section{Dr. Nicolas Berthet}

Département Zoonoses et Maladies Emergentes

Centre International de Recherches Médicales de Franceville (CIRMF)

Franceville (Gabon)

E-Mail nicolas.berthet@ird.fr 
The overwhelming presence of viruses in aquatic environments has attracted the attention of the scientific community [10-12]. Moreover, many studies have also targeted aquatic viruses essentially because of their devastating economic effects on aquaculture [13-17]. Indeed, the impact on the worldwide trade of some infected species, such as fishes or shrimps, has resulted in estimated losses of billions of US dollars [13, 18]. Nevertheless, viruses also play a central role in ecological niches, in terms of the variety of infected hosts and nutrient/carbon cycling, further fostering research in this group. In fact, aquatic viruses infect a wide range of aquatic species, from phyto- and zooplankton [3, 19], shrimp [20], fish [21], and seals [22], to even the largest animals in the oceans, whales [23]. The ability of viruses to infect such a wide variety of species indicates a remarkable capacity for adaptation and a potential public health hazard. For example, in 2011, an avian H3N8 virus caused the deaths of over 160 juvenile seals. This virus can be transmitted via respiratory droplets and it has already been involved in human pandemics $[24,25]$. All of these aspects bring viruses into the spotlight [26]. However, knowledge on aquatic viruses, their diversity, their transmission modes, or their reservoir(s) is relatively scarce, exemplifying an urgent need to dive deeper into this vast unexplored world. In this context, this review describes the latest developments of next-generation sequencing (NGS) tools in virology, from their emergence in the field of human health to their recent applications for the investigation of aquatic and, more specifically, fish viruses.

\section{Evolution of Technologies for Pathogen Discovery across the History of Virology}

The history of virology is tightly linked with the evolution of technologies that allowed major breakthroughs in the field. Technological developments during the last century have improved the detection and characterization of viral agents and have simultaneously led to a better understanding of their evolutionary history.

Viruses were first isolated on Chamberlain columns but, unlike most other microorganisms, viruses long remained invisible under conventional light microscopes. Furthermore, given that virus diameter varies from a few tens of nanometers to several hundreds of nanometers, the observation of viruses only became possible with the advent of electronic microscopy (EM) and its resolution on nanometer scales. With the visualization of viruses, virology then underwent an important development pro- cess because virus morphology constitutes a fundamental feature in the classification and recognition of viruses. One of the first EM applications in clinical virology was the distinction between poxviruses and the varicella-zoster virus $[27,28]$. Later developments, such as negative staining technology or immunoelectron microscopy, paved the way to a virological diagnosis and the detection of viral agents [29-31]. However, for better identification of viruses at the genus or the species level, EM generally must be combined with other methods such as cellular culture or molecular approaches. Because viruses are necessarily intracellular parasites, and symptomatic effects very often lag behind infection peaks, thereby hindering detection, viral replication in living cells was initially a prerequisite for viral identification. Historically, specific cells were used to isolate viruses either from cellular culture, embryonated eggs, or laboratory animals. These cells, traditionally derived from newborn mice (in the case of mammal viruses), constitute the classic tools for the isolation of a large spectrum of viruses from a wide diversity of biological samples. Therefore, viral replication in cellular culture, still considered the gold standard for diagnosis, remains a key feature for the discovery and in vitro investigation of novel viruses. The main advantages of cell replication-based methods for virological diagnosis include the potential for isolation and amplification of viruses, improved sensitivity compared with antigen-based detection methods, and the possibility to isolate unexpected infectious viruses. Although mammal virology has benefited from these advantages, cellular models are still needed in aquatic virology [32]. Despite the large number of fish cell lines that have been developed over the last few years, efforts are still needed for shellfish and other aquatic organisms for which cell culture is often inaccessible [33] and for which novel and integrative approaches remain to be designed $[34,35]$.

Since the advent of molecular biology, nucleic acidbased detection and identification methods have revolutionized virology and continue to play an important role in the detection and characterization of viral infections in many fields, including aquatic virology, at the fundamental and clinical levels. For instance, the polymerase chain reaction (PCR) is the most widely used method for viral detection [36-38]. One of its main strengths is its high sensitivity, although false negatives can occur when: (i) the viral load is below the threshold level, which is often the case in healthy carriers; (ii) the biological samples contain chemical or biological substances that inhibit the enzymatic amplification process; (iii) there is genetic divergence between the sequence of the screened agent and
286

Intervirology 2016;59:285-300 DOI: $10.1159 / 000477808$
Nkili-Meyong et al. 


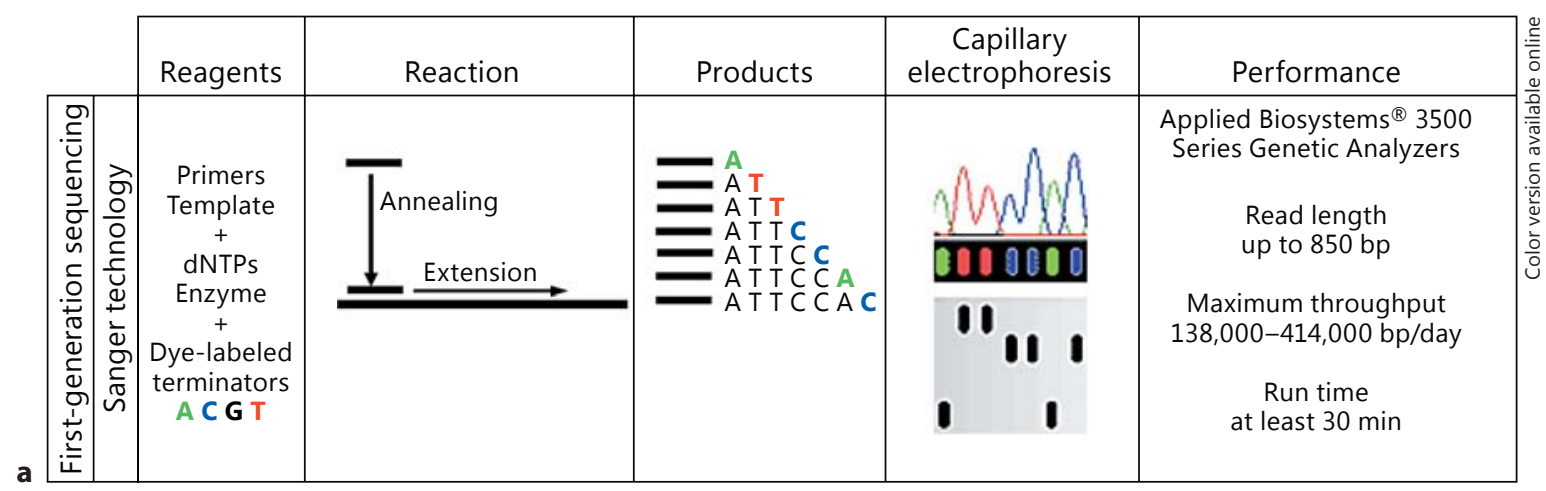

Fig. 1. Marketed sequencing platforms: from the first to the fourth generation. The chemical principle of the main sequencing technologies is illustrated. Information on the manufacturer, benchtop model, and sequencer performance is also given. a First-generation sequencing is represented by the Sanger technology implemented and released by Applied Biosystems. b $2 \mathrm{G}$ sequencing is illustrated by 3 distinct technologies from different manufacturers:

the primers used for the amplification of a targeted area, which is often the case for poorly characterized viruses such as aquatic ones [39], or (iv) the virus evolves rapidly, as is the case for RNA viruses, which undergo reassortment mechanisms. PCR generally targets one or at most a few species and variants. Nevertheless, identification of the pathogen can be performed quickly and directly on clinical or environmental samples, which can influence public health policy. More recently, high-throughput approaches, such as microarrays, have facilitated the parallel detection of a large number of pathogens, thus providing access to the high genetic diversity of viral agents [137]. Though very powerful, this technology still requires the a priori knowledge of viral sequences. This barrier has been overcome by the latest advances in sequencing technologies that have unlocked access to a wider world of viral agents, including those that cannot be readily grown or are not culturable, or those that persist and even develop in their environment before (re)emerging to give rise to sporadic or epidemic cases.

\section{From Sanger to NGS: Overcoming Technological Challenges}

\section{Sequencing Technologies}

Ever since genomic DNA was identified as the main tool for characterizing species and individuals, progress in nucleotide sequencing has been a basic challenge. Many improvements have indeed been made since the pyrosequencing by Roche, semiconductor ( $\mathrm{pH}$-based) sequencing by Life Technologies, and synthesis with reversible chain terminators by Illumina. c 3G sequencing uses single-molecule, real-time sequencing commercialized by Pacific Biosciences. d $4 \mathrm{G}$ offers single-molecule, real-time, and even portable sequencing commercialized by Oxford Nanopore Technologies.

(Figure continued on next pages.)

first descriptions of DNA sequencing in 1977 by Frederick Sanger and Walter Gilbert [40, 41]. Both methods are today referred to as first-generation sequencing technologies, with Sanger's method being adopted as the standard. Subsequent improvements have aimed at reducing, on the one hand, the cost of the overall sequencing process, and, on the other hand, increasing its efficiency and practicality. Major advances include, among others, the introduction of DNA amplification before sequencing or the development of fluorescence-based capillary electrophoresis (Fig. 1) [42]. Thus, since the first Sanger sequencer was put on the market in 1987, numerous technological challenges have been overcome, eventually leading to automated sequencing [43, 44]. However, despite these major advances, Sanger sequencing remained limited by: (i) the quantity of DNA required and the number of samples that could be treated simultaneously, (ii) the size of the sequenced DNA fragment (ranging from 0.5 to $1 \mathrm{~kb}$ ), and (iii) the low throughput of the process (only $115 \mathrm{~kb}$ /day for $1 \mathrm{~kb}$ length; Fig. 1). In the late 1990s, the human genome sequencing project gave rise to major improvements in sequencing technologies and approaches $[45,46]$ that quickly found numerous applications, including in virology. This project greatly contributed to the emergence of the so-called NGS, largely used for screening and characterizing pathogen communities [47], first in the human environment and then in environmental sciences, including aquatic virology. The first NGS apparatuses were developed and released in 2005 as the second generation $(2 \mathrm{G})$ of sequencers, and they intro-

Intervirology 2016;59:285-300 287

Contribution of NGS to Fish Virology 


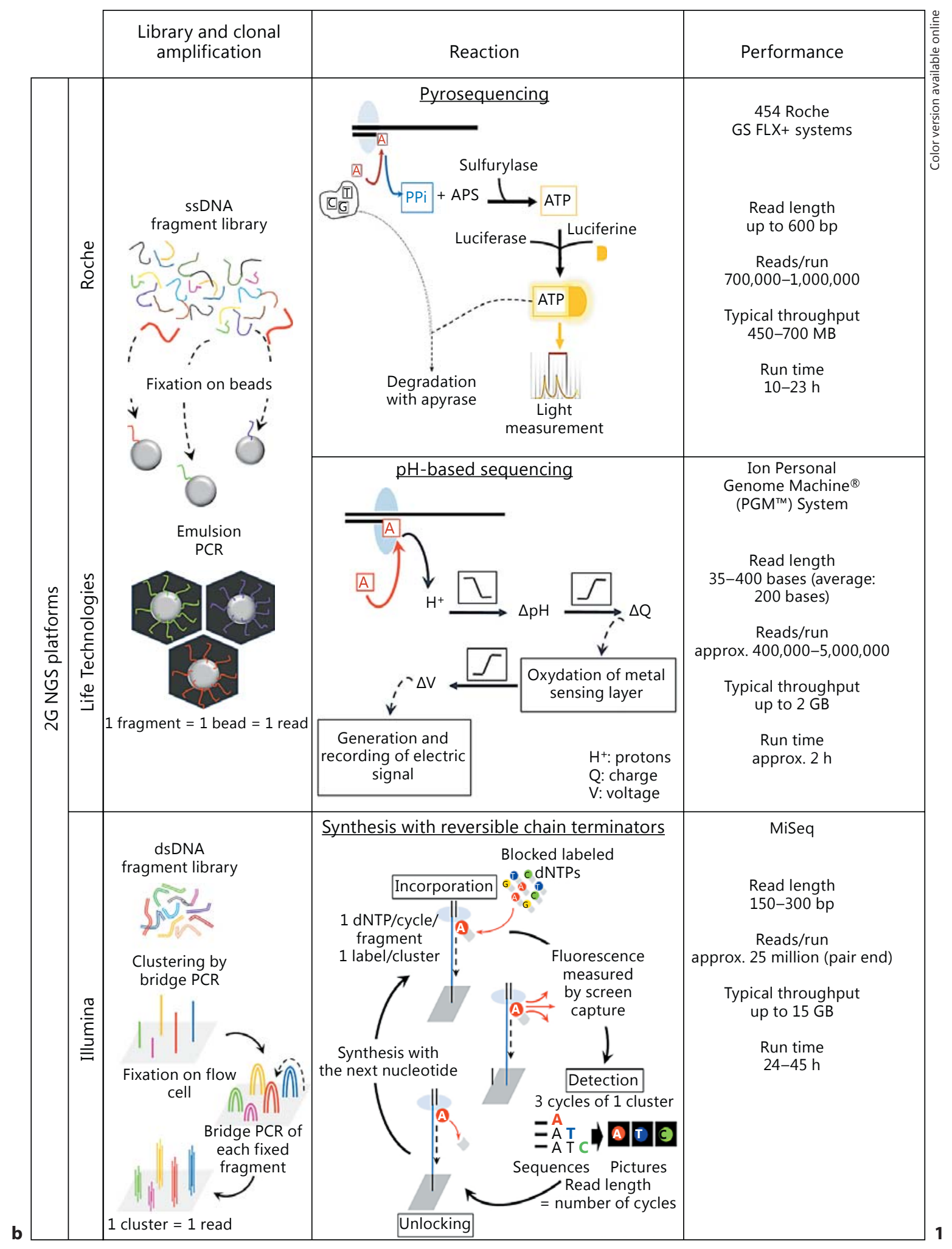

(Figure continued on next page.) 

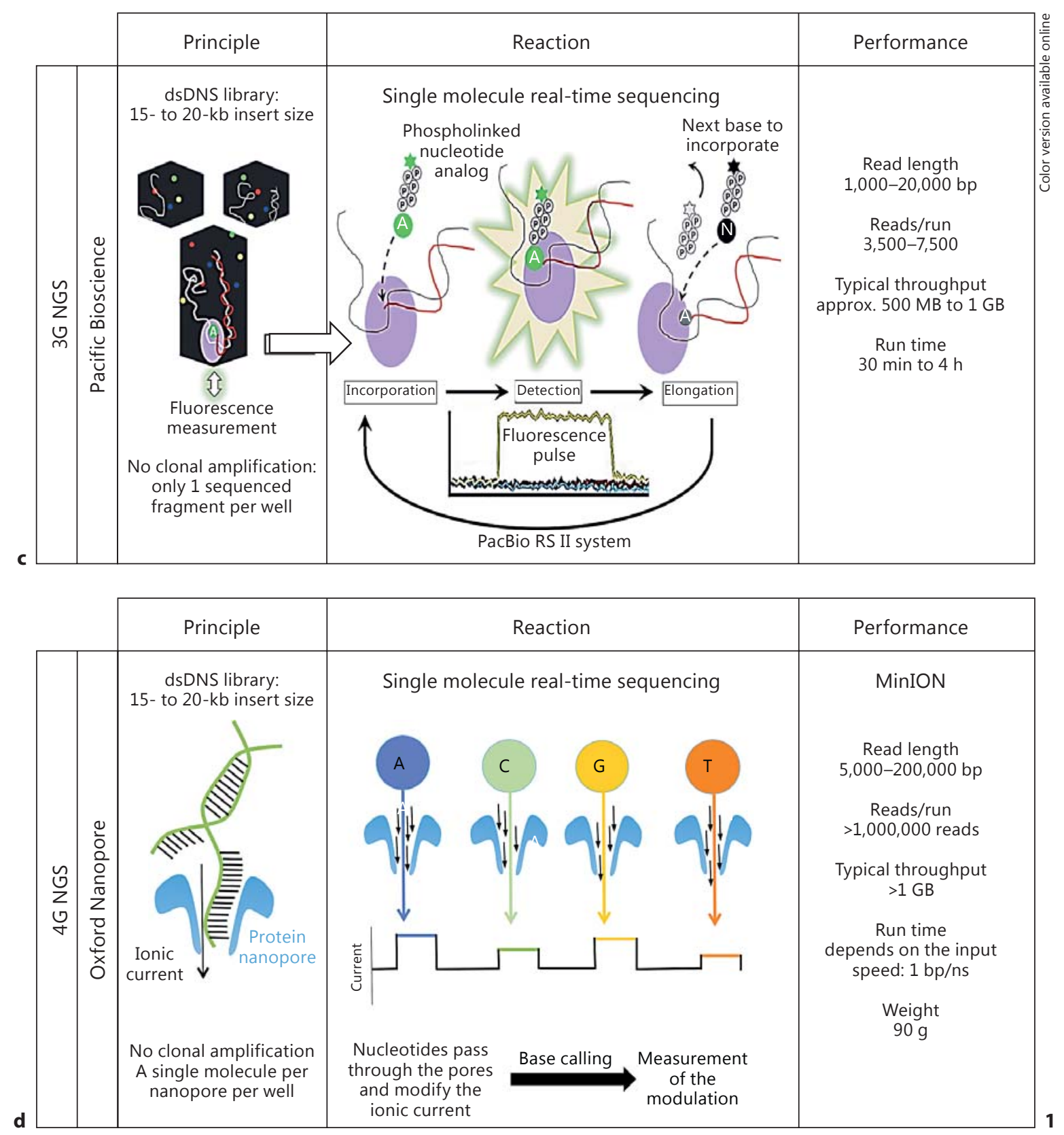

duced significant improvements in DNA amplification, sequencing chemistry, and fluorescence detection; they were also accompanied by powerful bioinformatics tools for treating the unprecedented amounts of generated data. NGS thus made it possible to carry out parallel analyses of complex microbial communities with high sensitivity. $2 \mathrm{G}$ technologies are mainly based on sequencing a huge number of short DNA fragments via distinct but simultaneous massive reactions, resulting in millions to billions of reads. They rely on clonal amplification that

Contribution of NGS to Fish Virology generates sequence-able clusters, but exploit a different type of sequencing chemistry. The first $2 \mathrm{G}$ sequencer to be commercialized (the 454 from Roche) was based on pyrosequencing and produced nearly 200,000 reads of $100-150 \mathrm{nt}$ in length, corresponding to approximately 20 $\mathrm{Mb}$ of output data [48]. The last version of the 454 (GS FLX titanium XL+) could generate up to 1,000,000 reads of $700 \mathrm{nt}$, corresponding to $700 \mathrm{Mb}$ of data (Fig. 1). The Roche 454 pyrosequencer is no longer marketed due to the development of other $2 \mathrm{G}$ platforms and the recent 
emergence of the third-generation $(3 \mathrm{G})$ sequencing technology [49].

In parallel, several other $2 \mathrm{G}$ platforms arose, further improving sequencing output by increasing the length, quantity, and quality of the generated sequences $[48,50]$. One leading $2 \mathrm{G}$ sequencing approach relies on enzymatic synthesis with reversible dye terminators. Initially developed by Solexa in 2006, this technology was acquired and improved by Illumina in 2007 [48, 51]. Illumina's platforms use a specific flow cell as a solid support carrying adapter sequences that bind the DNA fragments to be sequenced. Illumina's technology is also characterized by a clustering step based on clonal amplification carried out with a bridge PCR approach, thus making paired-end sequencing possible (Fig. 1) [48, 52]. The length of generated reads, as well as the quantity of output data, have significantly increased since, from $25 \mathrm{nt} / 1 \mathrm{~Gb}$ to up to 150 $\mathrm{nt} / 1,800 \mathrm{~Gb}$. Today, Illumina offers 2 main series of benchtop sequencers, namely MiSeq (Fig. 1) and NextSeq that provide $15 \mathrm{~Gb} / 25 \times 10^{6}$ reads and $120 \mathrm{~Gb} / 400 \times 10^{6}$ reads as maximum output data, respectively. The HiSeq series, incompatible with benchtop use, can generate up to $1,800 \mathrm{~Gb} / 6 \times 10^{9}$ reads. This scale of output ability allows for a large panel of biological applications as well as optimizing time and costs according to research needs [52-54].

More recently, another type of technology has been put on the market and is based on monitoring changes in $\mathrm{pH}$ (Ion Torrent, from Life Technologies). Developed in 2010, this brand offers several platforms that vary according to output data, namely Ion S5, Proton, and a benchtop version, the Ion PGM. The sequencing principle is completely different from the $2 \mathrm{G}$ sequencers Roche 454 and Illumina. The clonal amplification step involves emulsion PCR using small beads linking DNA fragments to oil micelles (as in the 454 system), and the sequencing process consists in measuring the variation in $\mathrm{pH}$ due to the release of $\mathrm{H}^{+}$protons during DNA synthesis (Fig. 1). Only uncoupled native nucleotides are used for DNA synthesis, and no specific marker is needed, wherein lies its major advantage. This semiconductor technology does not require any laser or scanner to read fluorescence, greatly simplifying the sequence-reading process and saving time. Moreover, this approach prevents the accumulation of background noise due to fluorophores. In comparison with Illumina's benchtop sequencer, for equivalent accuracy and sequence quality, the Ion PGM is more expensive (USD 1,000/1 Gb/run vs. USD 502 with Illumina) but much more rapid (2 h vs. approx. 27 h; Fig. 1) [55].
In 2009, Pacific Biosciences (PacBio) was the first company to commercialize $3 \mathrm{G}$ technology known as singlemolecule real-time (SMRT) DNA sequencing. Its technology is based on the direct monitoring of polymerase activity during the DNA synthesis with fluorescently labeled nucleotides allowing for real-time imaging of the newly synthesized DNA strand. Initially able to generate approximately 1,000 base reads, today PacBio platforms can produce reads of up to $10 \mathrm{~kb}$ within $2 \mathrm{~h}$ (Fig. 1; the longest generated read is approx. $54 \mathrm{~kb}$ ), thus helping to solve the genome assembly issue in part $[56,57]$. Despite this high efficiency, a 5-20\% error rate has been reported $[55,57$, 58]. The ongoing development of fourth-generation $(4 \mathrm{G})$ technologies could fill this gap by both increasing accuracy and reducing the time and cost of high-throughput sequencing. Possibilities include combining 3G singlemolecule sequencing with Nanopore technology, based on the ability of DNA molecules to pass through nanoscale diameter biopores. Oxford Nanopore Technology launched its MinION sequencer, which detects the specific electrical signature of each nucleotide after cleavage by an exonuclease of the single DNA molecule that passes through the pore [59]. The rapidity of the reaction $(20 \mathrm{~ms} /$ base), combined with the accuracy of the exonuclease reaction, holds great promise. Despite a reported high error sequencing rate, the MinION enabled the rapid sequencing of a full genome of influenza virus [60], or could achieve the identification of a virus at the strain level [61]. For a more detailed description of these technologies, readers can refer to Goodwin et al. [62].

\section{Preparation of Libraries for Viral Genome Detection:}

\section{Issues and Challenges}

As in all other fields of biology using NGS technologies, sample treatment and library preparation raise the issue of the pathogen detection threshold. The advantage, and also the main difficulty with NGS, is the ability to sequence all DNA present in a sample, which produces a large proportion of noisy data, potentially masking the targeted sequence. Bioinformatics tools may eventually be able to prune unwanted sequences; however, data that is clean from the start will facilitate the subsequent bioinformatics analyses. In aquatic metagenomics, the problem is particularly complex because samples may include high quantities of contaminants. Various filtration procedures, such as size fractioning, have been optimized to efficiently concentrate viruses and eliminate the main source of noisy sequences (e.g., eukaryotes, bacteria) [63, 64]. Ultimately, the real challenge lies in detecting the targeted viruses among all those present in the samples. 
The problem is slightly different when working directly on fish specimens, in which the quantity of contaminants is limited compared with water samples. Here, although viral diversity is restricted to the targeted host and host bacteria, the notion of viral load has a significant impact. It is extremely laborious to detect the genome of a virus present in low quantities. Viruses in low proportions in a sample cannot be detected without any prior enrichment strategy $[65,66]$. Several procedures have already been developed to enrich samples or derivative DNA/RNA. For example, DNase pretreatment [67] and rRNA removal $[68,69]$ are efficient and robust options for RNA virus exploration by respectively eliminating host DNA contaminants and host ribosomal RNA that represent more than $90 \%$ of the total RNA of a sample [63]. Another strategy consists in enriching studied samples with fractions that are likely to contain the targeted viral material. Random whole genome or transcriptome amplification based on nonspecific techniques can also be used $[63,70]$. However, the efficiency of this type of amplification for the most diluted fractions - namely viruses with very low loads - is still uncertain. Finally, it is important to first enrich the sample with the targeted viral fraction and then amplify it to ensure a higher efficacy [70, 71]. For these reasons, the option of targeted sequence capture systems is very attractive, because it can ensure specific selection, and thus specific enrichment, of targeted sequences [72]. These approaches, despite their promising efficiency, remain expensive and imply that the sequence of the targeted pathogen is known; they are thus not suitable for pathogen discovery [73]. Global enrichment processes by capture have already been tested and proven mainly in the field of the human virology [71, $74,75]$. Although they appear promising, their use is still limited in fish virology [76]. Considering the current state of the art, it is clearly necessary to optimize both library preparation, to increase the probability of sequencing the targeted viruses, and bioinformatics tools, to efficiently exploit the available data.

\section{Bioinformatics Challenges}

The complexity of analyzing fish viruses is intrinsically linked to their genomic diversity. Fish species represent about half of all known vertebrates and have colonized very different aquatic ecosystems, from marine to freshwater. This tremendous diversity of hosts and environments has certainly contributed to the extraordinary wealth in viruses that has been reported, particularly over the last decade, and which is undoubtedly only a small part of the existing virome.

Contribution of NGS to Fish Virology
Identification of Viral Organisms

The polyphyletic nature of viruses makes it even more complicated to find the proverbial needle in the haystack. Contrary to the 16S ribosomal RNA gene that is commonly used for bacterial taxonomic classification, there is no known sequence shared among all viruses $[77,78]$. A recent discovery revealed that ribonucleotide reductases (RNRs) can be used as potential viral markers because they are widely distributed among dsDNA viral families [79]. For instance, the predicted nucleic acid distribution among viroplankton indicates that dsDNA viruses can comprise $70 \%$ of the total viruses and that $93 \%$ of dsDNA viroplankton may contain RNRs [79, 80]. Moreover, RNRs are present in other viral lineages, such as cyanophages, iridoviruses, cyanopodoviruses, and many others.

However, ensuring accurate identification of short sequences (singletons and/or contigs) is difficult at best when no homologs are available in databases. Classification tools such as CLARCK or GOTTCHA can overcome these hurdles with their target-specific or unique signature approach $[81,82]$. However, unique signature models can be altered depending on how big the genome is and how sequence divergence is distributed across the genome. Consistently unique or specific k-mers will fail to be recognized in targeted reads if divergence is dispersed instead of being grouped throughout the genome. In parallel, standard mapping tools (e.g., Bowtie [83]) are not suitable for this situation, because they fail to correctly assign some reads related to similar virus types. Most commonly used mapping tools assume low divergence between datasets and references, and only some are more flexible regarding error rates, insertion/deletions (indels), or substitution [84]. New tools have been developed to overcome this issue and can correctly classify reads displaying high divergence with reference sequences: MaxSSmap and NexGenMap (both graphics processing unit programs) or Stampy (hash-based program) tolerate divergence up to 30,15 , and $10 \%$, respectively [85-87].

Lack of Dedicated Databases and Tools to Limit the

Amount of Unknown Data

Metagenomic sequencing gives a clear and sharp view of the microbial community present in a given sample. With its ability to detect uncultured microorganisms, this sequencing method can characterize the abundance and diversity of microorganisms that compose a sample and lead to a better understanding of the biological interactions in a community. Identifying new sequences relies heavily on the availability and quality of databases. There-

Intervirology 2016;59:285-300 DOI: $10.1159 / 000477808$ 
fore, database curation is of prime importance. Bioinformatics tools and databases dedicated to viral metagenomics have been reviewed elsewhere $[88,89]$. In terms of virus discovery, the purpose of these tools is to help identify viral species and characterize their diversity and their function. In this regard, there are 2 basic approaches to analyze metagenomics samples after sequence filtering. The first is a taxonomic classification based on reads to determine the diversity of species present followed by the assembly of organisms of the selected taxa [88]. The second involves de novo assembly based on the entire preprocessed set of reads where resulting contigs are classified $[90,91]$. In both cases, once a full genome has been covered, its characterization usually involves the prediction of possible ORFs and the comparison with those found in protein databases. Although efforts have been made to develop tools for viral discovery pipelines, namely ViromeScan and MetaVir2 [92, 93], database integration still requires improvements. The size of viral aquatic databases is growing and has the potential for tremendous increases because a vast number of viral organisms have yet to be discovered. However, these databases should not expand as a single structure isolated from other biological databases. Accordingly, Vinithkumar [94] proposed a multilinked approach, where databases could have their own internal compartmentalized structure while being integrated with one another. No matter how well curated, sequences without any similarities to any species recorded in the available databases remain unresolved. Due to the limits of similarity-based methods, new strategies have been developed to decipher this "unknown fraction." Because unrelated sequences are still a serious impediment to the understanding of marine viral communities, protein clustering (PC) has been used to organize the unassigned sequences. PC consists of predicting ORFs and then grouping sequences regarding their ORF similarities. Hurwitz and Sullivan [95] applied this method first as a way of mapping the ocean virome. Beyond sorting the unknown sequences, they highlighted the variation in functional viral diversity according to sampling parameters such as season, distance to shore, and depth. In the same year, Ignacio-Espinoza et al. [96] asserted that the marine viral diversity may be lower than the commonly accepted paradigm. The number of PCs as a function of the number of metagenomes appears to reach saturation near 30 metagenomes, showing that diversity stagnates despite the increasing number of genomes sequenced. Hurwitz et al. $[95,97]$ recently defined "core" PCs as the ones found in every sample of the Pacific Ocean virome and demonstrated that those "core"
PCs were more abundant in photic zones than in aphotic zones, assuming gene flow between surface waters and the depths. These examples demonstrate the type of information that clustering methods can provide. Another approach relies on artificial neural networks [98] for the identification of viral structural proteins, which are present in all viruses. These networks correctly classified major capsid and tail proteins of phages. The classification has been validated experimentally and turns out to be more sensitive than a commonly used pattern analysis tool, MEME [99]. However, this procedure is not straightforward because results may be distorted by network architecture (number of neurons and hidden layers), data complexity, or the training and validation datasets. Given that sequences populating those sets come from available databases, the whole process and its accuracy still depend, to a certain extent, on what is accessible. Considerable efforts have been made to label the unknown fraction and the new tools and methods are paving the way to a clearer picture of the aquatic viral world.

\section{Including the Host in the Analysis}

Likewise, another major challenge arises when viruses share homologies with their hosts. Here, recoverable viral data is hampered, because, insofar as possible, viral sequences must be distinguished from cellular signals. For example, the increasing number of complete genomes from marine viruses has led to the identification of auxiliary metabolic genes in cyanophages [93]. In addition to bona fide viral genes, viral genomes may also contain genes coding for proteins involved in photosynthesis [100], overturning the idea that viruses only carry genes responsible for viral reproduction. These genes, shared by viruses and bacteria, need to be differentiated to retrieve correctly only the virome component of the studied samples. Consequently, new computational approaches that discriminate viral and host versions of photosynthesis genes have emerged [101]. The use of support vector machines (SVMs) has helped to solve such taxonomic problems. SVMs are learning algorithms designed for binary qualitative variable prediction. Determining a classifier or a discrimination function with the greatest forecast quality guides the prediction. Here, discriminating viral from bacterial genes is similar to discriminating a dichotomous variable; in this case, SVMs are able to correctly separate fragments without adhering to previous observations. They have been used to classify core photosystem II genes of cyanobacteria and cyanophages, and were even tested on partial sequences with good performance [101].
292

Intervirology 2016;59:285-300 DOI: $10.1159 / 000477808$
Nkili-Meyong et al. 
Fig. 2. Viral genome assembly and viral diversity. Longer "true" contigs are produced when the genomes included in the sequencing sample share fewer similarities (high intertaxon diversity) than in a multiinfection-like case (high intrataxon diversity). In the latter case, contigs are generally shorter and some may be chimeric.

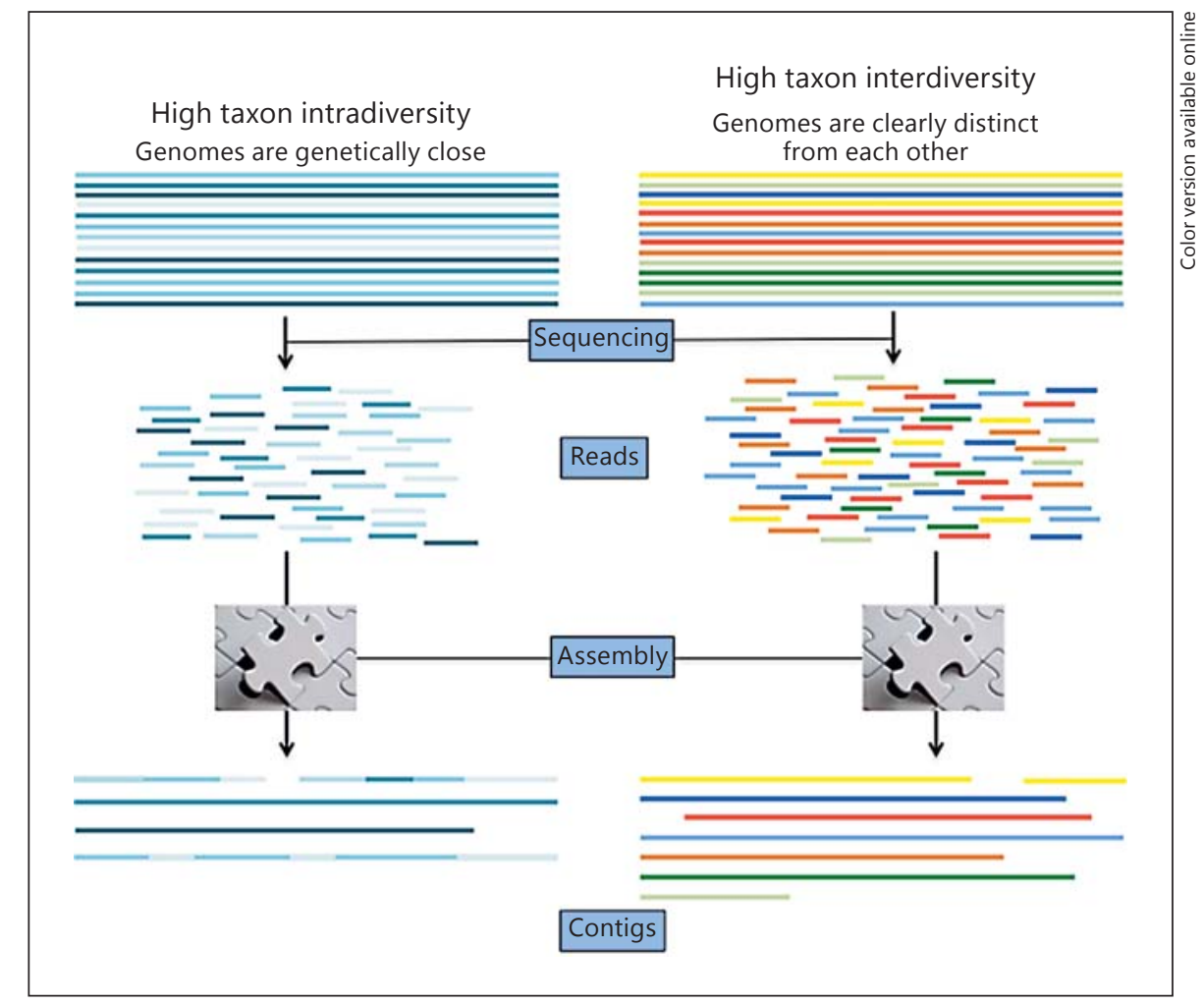

Challenges in Assembling Fish Viral Genomes in Metagenomics

In aquatic viral metagenomics, whole genome sequencing is required for better virus characterization. Unfortunately, high genetic diversity implies more complexity in the assembly process [102]. "High diversity" can involve: (i) high intertaxon diversity, whereby a taxon has many members that are not necessarily genetically remote from one another, or (ii) high intrataxon diversity, whereby a taxon shows large dissimilarities between members. Each situation can lead to different approaches regarding assembly (Fig. 2) or taxonomic classification. First, for genome assembly, high intrataxon diversity is bothersome in cases of multi-infection, because assembling short reads from close viruses from the same taxon can lead to chimeric contigs. Closely related sequences lead to similar k-mers, resulting in false paths in the graph assembly [103-105]. A sample of water containing such genetically close viral particles would thus be assimilated to a multi-infection case. In contrast, high intertaxon diversity can ease the assembly step since k-mers in the data set would be quite distinct from one another. Additionally, uneven coverage is also problematical for the assembly step because coverage variations may result in loss of

Contribution of NGS to Fish Virology accuracy. Many assemblers assume uniform coverage, with some of them removing low coverage regions, yielding fragmented assemblies [102, 106, 107]. Assemblers successfully used in single cell sequencing should be preferred since they have been designed for handling nonuniform coverage [108-110].

Bioinformatics regarding $3 \mathrm{G}$ and $4 \mathrm{G}$ Sequencing

Novel sequencing technologies ( $3 G$ and $4 G$ ) rely on single molecules, and as such do not require any amplification steps prior to sequencing. In addition to removing the potential biases induced by amplification [111, 112], these technologies will very soon change challenging issues regarding bioinformatics analysis. For instance, the read assembly issue will no longer deal with "putting small parts together in the right order" since longer reads will be produced with $3 \mathrm{G}$ and $4 \mathrm{G}$ sequencing methods. The assembly of 100-bp sequences is not the same problem as assembling 1,000-bp sequences, especially concerning k-mer and overlap sizes. Longer reads should facilitate assembly because longer $\mathrm{k}$-mers involve fewer computational operations; for overlap layout consensusbased methods, it will require fewer operations to compute overlaps and less ambiguity related to repeats; for the

Intervirology 2016;59:285-300 293 
de Bruijn graph-based approaches, it means fewer edges and possibly less ambiguity (bulges and alternative paths). Also, most medium-size repeats (measuring a couple of kilo base pairs) will be solved with longer k-mers. Nevertheless, current mapping tools will also benefit from 3G/4G sequencing. k-mer size depends on read size. Hence, assembly with larger k-mer sizes and fewer reads should be faster. More specifically, $3 \mathrm{G} / 4 \mathrm{G}$ provide a single copy of a genomic region, whereas $2 \mathrm{G}$ returns a larger depth of coverage with multiple copies of given regions. Therefore, mapping with $3 \mathrm{G} / 4 \mathrm{G}$ reads will require fewer operations by avoiding redundant computation. Even assembly validation using read mapping will be irrelevant knowing that coverage will no longer be an important issue. When it comes to the taxonomic classification of reads, the result can be questionable with low-load entities, which may be represented by a few reads and in extreme cases by only one read. Classification based on only one short read is not very reliable, particularly in cases of multi-infections. Obviously, longer reads allow more robust classification calls. Organisms identified with a very low proportion of reads are commonly thought to result from contamination. For this reason, contamination is a thorny issue because the difference between low loads and contamination cannot be solved. Unfortunately, no sequencing technologies are $100 \%$ error free and $3 \mathrm{G} / 4 \mathrm{G}$ is no exception [57-59]. Therefore, assembled genomes from longer reads that may contain errors can be misinterpreted as possible variants. Single error-prone copies of genomic regions can lead to calling false SNPs (single nucleotide polymorphisms), contrary to $2 \mathrm{G}$ with sufficient coverage depth for reliable SNP calls. New bioinformatic challenges will therefore arise with the emergence of $3 \mathrm{G} / 4 \mathrm{G}$.

\section{Portability and Field Sequencing}

Another feature of $4 \mathrm{G}$ sequencing that may be particularly relevant to aquatic/fish virology is its compatibility with field experiments. In this regard, the ultra-portable MinION device from Oxford Nanopore Technologies showed good performances in terms of rapidity and robustness in difficult environments $[113,114]$. Combined with the newly launched VolTRAX device for automated library preparation, Oxford Nanopore Technologies is about to provide a complete and fully portable sequencing workflow for nonlaboratory environments (https:// nanoporetech.com/publications/voltrax-rapidprogrammable-portable-disposable-device-sample-andlibrary-preparation). Although this technology still requires a deep evaluation, especially with regards to the nature of input material and the limit of detection, it seems very promising for the quick detection and identification of viruses from water or fish samples. Finally, single molecule-based technologies will also dramatically reduce the required amount of input DNA (or RNA), and in turn increase the ability to detect viruses at low concentrations.

\section{Applications of NGS to Fish Virology: Some Successful Examples}

\section{Discovery of New Viruses}

An interesting application of NGS is the search for viruses as etiological agents of new syndromes. This approach is extremely interesting when all the traditional methods to identify viruses have failed and when the viral pathogen is not culturable in vitro. One example is the HSMI (heart and skeletal muscle inflammation) of salmon, a fatal disease that appeared in 1999 in hundreds of farms in Norway and the UK and remained unexplained for a decade. The presence of an infectious agent was demonstrated by horizontal transmission experiments, but it was only in 2010 that a virus was identified using NGS. Total RNAs were extracted from the heart (a putative target of this agent) and serum, and were pyrosequenced. This approach led to the identification of a new virus related to the Reoviridae and named piscine reovirus (PRV) [115]. Although Koch's postulate was not fulfilled, several pieces of evidence point to the implication of PRV in the syndrome. During the same period, a second novel virus was identified by NGS from salmon affected by cardiomyopathy syndrome (CMS), which is similar in some aspects to HSMI. Using GS FLX titanium chemistry, sequences identical to those of PRV were found, but a new virus, related to the totivirus genus, was also identified in the same samples [116, 117]. Further research suggested that this piscine totivirus was the causative agent of cardiomyopathy syndrome, whereas PRV may only have been an opportunistic agent. Indirect evidence involving the totivirus was the absence of any other viral sequences in the massive set of reads produced. Another example is the recent description of the so-called tilapia lake virus (TiLV). Ion torrent sequencing of cDNA libraries built from RNA extracted from the brain of diseased tilapia led to the identification of an orthomyxolike virus as the etiological agent of a disease responsible for mass mortalities of tilapia in Israel [13]. The segmented RNA genome of this new virus, tentatively named TiLV, shows almost no homology with any known se-
294

Intervirology 2016;59:285-300 DOI: $10.1159 / 000477808$
Nkili-Meyong et al. 
quence, except for 1 segment. Surprisingly, sequencing the genome of a TiLV PCR-positive sample from a diseased fish in Ecuador showed $>97 \%$ nucleotide identity with the Israeli virus. Given that the clinical signs observed in Ecuador were very different from those observed in Israel, these findings indicate that a similar (or nearly similar) viral agent may be responsible for 2 diseases in 2 distant geographical locations. These data also highlight how an emerging virus can rapidly become a global threat for an important aquaculture species.

Although from these examples it appears that NGS may provide clues to explain new pathologies, complementary evidence is still needed to link formally identified viral sequences to specific symptoms and to verify Koch's postulates. This issue is well illustrated by the recent findings of 3 viruses from different families in a single sea bream (Sparus aurata) affected by lymphocystis disease, which is frequent in the Mediterranean region and generally attributed to an iridovirus (LCDV). In this study, the combination of 454-Roche and Illumina sequencing identified not only an LCDV genome very distinct and much longer than the ones already known, but also new viruses from the papillo- and a polyomavirus families. This finding raised the issue of the respective roles of these new viruses in triggering the disease [118].

\section{Contribution of Full-Genome Sequencing to}

Taxonomy and Classification

Another application of NGS is the full-length sequencing of already described viruses, for which complete genomes are likely to provide more complete phylogenetic and/or epidemiological information. In a recent study, full-genome sequencing of the European sheatfish virus (ESV), a ranavirus from the Iridoviridae family, was useful to genetically distinguish it from epizootic hematopoietic necrosis virus (EHNV), another ranavirus [119]. Before this sequencing work, ESV and EHNV were differentiated in testing laboratories by sequencing a short conserved region of the major capsid protein, with the viruses differing by only a few nucleotides in this portion. The alignment of full-length EHNV and ESV genomes shows many more differences at the genome scale, such as indels and inversions, which will be useful for designing a simple PCR-based diagnostic test not relying on sequencing. Full-genome sequencing has also successfully been applied to cyprinid herpesvirus 2 ( $\mathrm{CyHV}-2)$, which is responsible for a severe pathology in goldfish [120] and more recently for cyprinid herpesvirus 3 (CyHV-3) [121]. The complete sequence of the 290-kb-long CyHV-2 genome has been compared with those of 2 other cyprinid

Contribution of NGS to Fish Virology herpesviruses, namely CyHV-1 and CyHV-3, infecting the common and ornamental carps (Cyprinus carpio). Partial sequences previously obtained by PCR as well as distinct biological properties can distinguish the 3 herpesviruses. However, alignment of their complete genomes revealed significant genetic differences, with genes or blocks of genes rearranged between the viruses. For instance, ORF4 present in the terminal repeat of CyHV-3 is inverted and located in the unique region of CyHV-2.

Although whole-genome sequencing has helped to distinguish CyHVs in a phylogenetic perspective, the poor understanding of the function of the genes prevents the elucidation of the biological differences between species. However, the complete sequencing of a series of variants of $\mathrm{CyHV}-3$, possibly less pathogenic than the typical virulent strains and for which only short sequences are available, would certainly help formulate hypotheses on the function of some genes involved in virulence [39].

\section{Evolution and Virulence}

NGS greatly improves the understanding of the evolution of piscine viruses, and more specifically their pathogenicity/virulence. The infectious salmon anemia virus (ISAV), a devastating virus in the salmon industry, is the best example of the use of NGS in the study of the evolution of virulence in a fish virus. ISAV is an orthomyxovirus, of which the major surface glycoproteins, fusion protein $(\mathrm{F})$ and hemagglutinin-esterase (HE), have a crucial function in virus uptake and the release of viral particles, respectively [122]. The HE protein contains a highly polymorphic region (HPR), the size of which has a strong impact on the virulence of the virus. A full-length HPR (HPR0) is associated with avirulent strains, not culturable and primarily found in the gills, while shortened HPR versions are associated with virulent viruses (vISAV), systemic in the fish and responsible for severe losses. In addition to the HPR of HE, a single amino acid in the F gene is correlated with virulence. A common view is that the avirulent strains circulate in reservoirs and that some deleted variants appear. Although the mechanisms of action of the proteins are rather well understood, the genomic transition of full-length viral populations to strains harboring deletions was poorly documented until recently [123]. By performing ultra-deep sequencing targeting the $F$ and HE genes of viruses in the same location before and after an outbreak, the composition of different quasi-species could be elucidated, which in turn led to several hypotheses regarding their link with the different patterns of virulence [124]. Intrasample genetic variation, not detected by Sanger sequencing, was found for each type of

Intervirology 2016;59:285-300 DOI: $10.1159 / 000477808$ 
sample. Surprisingly, there were more mutants in samples before the outbreak than after. Mutations were more concentrated in the HPR region compared with the other parts of $\mathrm{F}$ and HE. A total of 14 deletion types were observed. Importantly, both deleted and nondeleted variants were found in fish before and after the outbreak. Moreover, low-frequency reads identified deleted variants in fish before the outbreak, a result with important consequences in terms of diagnosis in cases where the PCR-Sanger method did not detect these variants. Among all the variants found in fish before the outbreak, one carried a single mutation which was of particular interest because it dramatically changed the predicted secondary structure of HE RNA. The authors suggested that this new structure was more prone to deletion events. This hypothesis suggests that the intrasample genetic diversity includes variants for which the potential for change to higher virulence may differ.

There is less documentation on viral hemorrhagic septicemia virus (VHSV), a novirhabdovirus responsible for severe outbreaks in farmed rainbow trout. There are 4 main genotypes (I-IV) and a considerable number of variants, some with very different virulence levels. Historically, the virulent strains were thought to originate from avirulent strains circulating among wild marine fish before spreading through the trade of infected fish. It was surmised that a few mutations were responsible for changes from low to high virulence $[125,126]$. However, it has not been established whether these virulent variants preexisted in wild fish or if they arose and were selected in farmed trout. In a recent study, ultra-deep sequencing on 4 "isolates" of VHSV were passaged in vitro [127] showed that the number of variants within a specimen is very variable, from 100 to only 3 . No fewer than 89 polymorphic sites were observed for single isolate specimen. The authors deliberately excluded poorly represented $(<5 \%)$ variants which may have arisen from artifacts. Although the links between virulence and sequence diversity need to be clarified, these findings illustrate the great diversity of genotypes that can co-occur within a single specimen. They also highlight the importance of sequencing viral genomes directly from their hosts, especially for gaining insights into their evolution and pathogenesis. To this end, TGE (targeted genomic enrichment) may be very useful to overcome the high discrepancy in the proportions of cellular and viral genomic DNA in raw samples obtained from infected tissues. TGE has been described for a large range of applications [72], but surprisingly, the latter in virology has remained very limited. As far as we know, the only examples of successful use in- volve human herpesviruses $[128,129]$. In the latter study, authors accurately quantified the allele frequencies of viral populations contained in herpes zoster skin lesions and studied the pathogenesis of varicella-zoster virus and its attenuated vaccine strain. In a very recent study, 10 complete genomes of CyHV-3 were recovered directly from infected carp tissues in a single sequencing run, with the mean read depth varying from $219 \times$ to $9,179 \times$ [76]. Using this strategy, it now seems possible to study the dynamics of in vivo infections and to trace outbreaks of this deadly virus. For comparison, 24 genomic DNA libraries of Epstein-Barr virus were needed to recover 1 full genome from a tumor tissue with an average read depth of $17 \times[130]$.

NGS was also recently applied to identify microRNAs (miRNAs) in cells infected by CyHV-3, which displays the largest genome among herpesviruses known so far $(295 \mathrm{kbp})$. Preliminary bioinformatics analysis of the viral genome suggested the presence of pre-miRNA, and deep sequencing of the microtranscriptome confirmed the existence of some of the predicted miRNAs [131]. Two pre-miRNAs were found in cells infected in vitro and the corresponding miRNAs were detected in infected animals. There is experimental evidence that the most highly expressed miRNAs are able to regulate the expression of ORF123, the function of which is unknown. Furthermore, some of these miRNAs are conserved in the 2 other cyprinid herpesviruses, CyHV-1 and CyHV-2, suggesting an important function of these sequences. Although much work is still needed to understand the role of miRNAs in the virulence of CyHV-3, and of other aquatic viruses, NGS definitely opens new avenues of investigation.

\section{Characterization of Viromes through Metagenomics}

The presence of fish viruses in the water has been rarely documented due to their low concentrations in the environment. Metagenomics provides new opportunities to detect already-known viruses as well as to discover new viruses, both in marine and freshwater environments. As such, this type of approach has great potential for epidemiology because it offers the possibility to study the persistence and/or the spread of pathogenic viruses. One application is the search for pathogens in ballast waters which are transported worldwide and contaminate new ecosystems. In this regard, the presence of nucleic acids related to several pathogenic viruses was investigated in the ballast waters of boats in the North American Great Lakes region [132]. It is estimated that 6.6 million tons of water is discharged annu-
296

Intervirology 2016;59:285-300

DOI: $10.1159 / 000477808$
Nkili-Meyong et al. 
ally from boats in the Great Lakes, which poses a serious threat for the introduction of new organisms and pathogens in the whole region. The emerging genotype IV of VHSV may have been introduced this way. In an attempt to characterize the viromes present in the ballast waters, viral nucleic acids extracted from $60 \mathrm{~L}$ sampled from several boats were sequenced. Among all the contigs identified, several exhibited genetic links either with a betanodavirus, a megalocytivirus, or $\mathrm{CyHV} 3$, which are all among the most economically important fish viruses. Unfortunately, the complete sequences of these viruses could not be obtained, probably due to an insufficient number of reads and/or an insufficient volume of water analyzed, combined with the difficulty of assembling rare sequences in contigs, as explained above. Such obstacles will certainly be overcome in the near future with the dramatic increase of the read length forecasted with the emergence of $3 \mathrm{G}$ and $4 \mathrm{G}$ technologies. Therefore, the number of reads appears to have crucial importance, not only to ensure an adequate coverage of a targeted viral genome (as highlighted in the previous section), but also to reduce the probability of missing rare sequences.

\section{Conclusions and Avenues for Future Research}

To conclude, the different technical approaches for virological diagnosis have improved according to scientific discoveries and technological innovations. Traditional techniques, such as cellular culture and immunological methods, have significantly contributed to the identification of numerous pathogens during the last century, whereas modern molecular methods such as PCR or microarrays have played an ever increasing role in clinical virology in the last decade. Methods based on metagenomics have allowed significant advances in the identification of pathogens directly from a biological sample, bypassing the need for cell cultures or for any a priori knowledge on the potential agents present. NGS and bioinformatics analysis have now become essential tools for viral pathogen discovery, for screening viromes, and for monitoring potential emerging pathogens. In this regard, the recently developed portable sequencers $(4 \mathrm{G})$ offer new perspectives through their ability to rapidly produce sequencing data outside laboratory facilities. Although the error rate is high today, one can reasonably expect that technological improvements will soon be made to decrease this rate to an acceptable range. If this is the case, this new generation of sequencers will dra-

Contribution of NGS to Fish Virology matically increase our capacity to monitor potential emerging pathogens.

However, associating a candidate pathogen with a disease will still remain a key issue, particularly considering Koch's postulate or Rivers' modification [133, 134]. In practice, these postulates are not always entirely met because some viruses still resist isolation and culture. The initial criteria have since been revised to include the use of nucleic acid-based detection methods $[135,136]$. Sequencing without prior knowledge of what is in the sample widens the scope of viral discovery. With its great diversity and abundance, the marine/aquatic virome may harbor viral pathogens that can trigger an epidemic in fish, and potentially in other organisms. Consequently, increasing our knowledge on fish and other aquatic viruses requires the development of sharper methods and tools for both molecular and bioinformatics analyses, which fit with the ever-changing sequencing technologies.

\section{Acknowledgements}

We acknowledge Heïdi Lançon and Dr. Carolyn Engel-Gautier for the revision of English usage. The CIRMF is supported by the government of Gabon, Total-Fina-Elf Gabon, and the Ministère de la Coopération Française. This review article was also made possible by the ERA-NET EMIDA-funded project MOLTRAQ (molecular tracing of viral pathogens in aquaculture).

\section{Disclosure Statement}

The authors declare that they have no competing interests.

\begin{tabular}{|c|c|}
\hline References & $\begin{array}{l}1 \text { Bergh O, Borsheim KY, Bratbak G, Heldal M: } \\
\text { High abundance of viruses found in aquatic } \\
\text { environments. Nature 1989;340:467-468. } \\
2 \text { Hara S, Terauchi K, Koike I: Abundance of } \\
\text { viruses in marine waters: assessment by epi- } \\
\text { fluorescence and transmission electron mi- } \\
\text { croscopy. Appl Environ Microbiol 1991;57: } \\
\text { 2731-2734. } \\
3 \text { Suttle CA: Viruses in the sea. Nature 2005; } \\
\text { 437:356-361. } \\
4 \text { Prostor LM, Fuhrman JA: Viral mortality of } \\
\text { marine bacteria and cyanobacteria. Nature } \\
\text { 1990;343:60-62. } \\
5 \text { Suttle CA: Marine viruses - major players in } \\
\text { the global ecosystem. Nat Rev Microbiol } \\
\text { 2007;5:801-812. } \\
6 \text { Wen K, Ortmann AC, Suttle CA: Accurate es- } \\
\text { timation of viral abundance by epifluores- } \\
\text { cence microscopy. Appl Environ Microbiol } \\
\text { 2004;70:3862-3867. }\end{array}$ \\
\hline
\end{tabular}

Intervirology 2016;59:285-300 297 
7 Marhaver KL, Edwards RA, Rohwer F: Viral communities associated with healthy and bleaching corals. Environ Microbiol 2008;10: 2277-2286.

8 McDaniel L, Breitbart M, Mobberley J, Long A, Haynes M, Rohwer F, Paul JH: Metagenomic analysis of lysogeny in Tampa Bay: implications for prophage gene expression. PLoS One 2008;3:e3263.

9 Yin Y, Fischer D: Identification and investigation of ORFans in the viral world. BMC Genomics 2008;9:24.

10 Fuhrman JA: Marine viruses and their biogeochemical and ecological effects. Nature 1999;399:541-548.

11 Wilhelm SW, Suttle CA: Viruses and nutrient cycles in the sea: viruses play critical roles in the structure and function of aquatic food webs. BioScience 1999;49:781-788.

12 Wommack KE, Colwell RR: Virioplankton: viruses in aquatic ecosystems. Microbiol Mol Biol Rev 2000;64:69-114.

13 Bacharach E, Mishra N, Briese T, Zody MC, Kembou Tsofack JE, Zamostiano R, Berkowitz A, Ng J, Nitido A, Corvelo A, Toussaint NC, Abel Nielsen SC, Hornig M, Del Pozo J, Bloom T, Ferguson H, Eldar A, Lipkin WI: Characterization of a novel orthomyxo-like virus causing mass die-offs of tilapia. MBio 2016;7:e00431-e00416.

14 Bloch B, Gravningen K, Larsen JL: Encephalomyelitis among turbot associated with apicornavirus-like agent. Dis Aquat Organ 1991; 10:65-70.

15 van Hulten MC, Witteveldt J, Peters S, Kloosterboer N, Tarchini R, Fiers M, Sandbrink H, Lankhorst RK, Vlak JM: The white spot syndrome virus DNA genome sequence. Virology 2001;286:7-22.

16 Yoganandhan K, Leartvibhas M, Sriwongpuk S, Limsuwan C: White tail disease of the giant freshwater prawn Macrobrachium rosenbergii in Thailand. Dis Aquat Organ 2006;69:255258

17 Zhang S, Shi Z, Zhang J, Bonami JR: Purification and characterization of a new reovirus from the Chinese mitten crab, Eriocheir sinensis. J Fish Dis 2004;27:687-692.

18 Mardones F, Perez A, Sanchez J, Alkhamis M, Carpenter T: Parameterization of the duration of infection stages of serotype $\mathrm{O}$ footand-mouth disease virus: an analytical review and meta-analysis with application to simulation models. Vet Res 2010;41:45.

19 Dunlap DS, Ng TF, Rosario K, Barbosa JG, Greco AM, Breitbart M, Hewson I: Molecular and microscopic evidence of viruses in marine copepods. Proc Natl Acad Sci USA 2013; 110:1375-1380.

20 Lightner DV: Virus diseases of farmed shrimp in the Western Hemisphere (the Americas): a review. J Invertebr Pathol 2011;106:110-130.

21 Walker PJ, Winton JR: Emerging viral diseases of fish and shrimp. Vet Res 2010;41:51

22 Bodewes R, Morick D, van de Bildt MW, Osinga N, Rubio Garcia A, Sanchez Contreras GJ, Smits SL, Reperant LA, Kuiken T, Osterhaus AD: Prevalence of phocine distemper virus specific antibodies: bracing for the next seal epizootic in north-western Europe. Emerg Microbes Infect 2013;2:e3.

23 Birkun AA Jr: Viruses of whales and dolphins (in Russian). Mikrobiol Z 1996;58:100-106.

24 Karlsson EA, Ip HS, Hall JS, Yoon SW, Johnson J, Beck MA, Webby RJ, Schultz-Cherry S: Respiratory transmission of an avian $\mathrm{H} 3 \mathrm{~N} 8$ influenza virus isolated from a harbour seal. Nat Commun 2014;5:4791.

25 Valleron AJ, Cori A, Valtat S, Meurisse S, Carrat F, Boelle PY: Transmissibility and geographic spread of the 1889 influenza pandemic. Proc Natl Acad Sci USA 2010;107:8778-8781.

26 Suttle CA, Chan AM, Cottrell MT: Infection of phytoplankton by viruses and reduction of primary productivity. Nature 1990;347:467-469.

27 Nagler FP, Rake G: The use of the electron microscope in diagnosis of variola, vaccinia, and varicella. J Bacteriol 1948;55:45-51.

28 van Rooyen CE, Scott GD: Smallpox diagnosis with special reference to electron microscopy. Can J Public Health 1948;39:467-477.

29 Gust ID, Kaldor J, Cross GF, Waugh M, Ferris AA: Virus-like particles associated with a faecal antigen from hepatitis patients and with Australia antigen. Aust J Exp Biol Med Sci 1971;49:1-9.

30 Kapikian AZ, Wyatt RG, Dolin R, Thornhill TS, Kalica AR, Chanock RM: Visualization by immune electron microscopy of a 27-nm particle associated with acute infectious nonbacterial gastroenteritis. J Virol 1972;10:1075-1081.

31 Welch AB: Purification, morphology and partial characterization of a reovirus-like agent associated with neonatal calf diarrhea. Can J Comp Med 1971;35:195-202.

32 Villena AJ: Applications and needs of fish and shellfish cell culture for disease control in aquaculture. Rev Fish Biol Fish 2003;13:111140.

33 Rinkevich B: Cell cultures from marine invertebrates: new insights for capturing endless stemness. Mar Biotechnol (New York) 2011; 13:345-354.

34 Pernet F, Lupo C, Bacher C, Whittington RJ: Infectious diseases in oyster aquaculture require a new integrated approach. Philos Trans R Soc Lond B Biol Sci 2016;371.

35 Burge CA, Friedman CS, Getchell R, House M, Lafferty KD, Mydlarz LD, Prager KC, Sutherland KP, Renault T, Kiryu I, VegaThurber R: Complementary approaches to diagnosing marine diseases: a union of the modern and the classic. Philos Trans R Soc Lond B Biol Sci 2016;371:20150207.

36 Cobo F: Application of molecular diagnostic techniques for viral testing. Open Virol J 2012;6:104-114.

37 Hayden R, Persing DH: Diagnostic molecular microbiology. Curr Clin Top Infect Dis 2001; 21:323-348.

38 van Belkum A, Niesters HG: Nucleic acid amplification and related techniques in microbiological diagnostics and epidemiology. Cell Mol Biol 1995;41:615-623.

39 Engelsma MY, Way K, Dodge MJ, Voorbergen-Laarman M, Panzarin V, Abbadi M, ElMatbouli M, Frank Skall H, Kahns S, Stone DM: Detection of novel strains of cyprinid herpesvirus closely related to koi herpesvirus. Dis Aquat Organ 2013;107:113-120.

40 Maxam AM, Gilbert W: A new method for sequencing DNA. Proc Natl Acad Sci USA 1977;74:560-564.

41 Sanger F, Nicklen S, Coulson AR: DNA sequencing with chain-terminating inhibitors. Proc Natl Acad Sci USA 1977;74:5463-5467.

42 Mardis ER: Next-generation sequencing platforms. Annu Rev Anal Chem 2013;6:287303.

43 Ansorge W, Sproat BS, Stegemann J, Schwager $\mathrm{C}$ : A non-radioactive automated method for DNA sequence determination. J Biochem Biophys Methods 1986;13:315-323.

44 Ansorge W, Sproat B, Stegemann J, Schwager C, Zenke M: Automated DNA sequencing: ultrasensitive detection of fluorescent bands during electrophoresis. Nucleic Acids Res 1987;15:4593-4602.

45 Lander ES, Linton LM, Birren B, et al; International Human Genome Sequencing Consortium: Initial sequencing and analysis of the human genome. Nature 2001;409:860-921.

46 Venter JC, Adams MD, Myers EW, et al: The sequence of the human genome. Science (New York) 2001;291:1304-1351.

47 Naidoo N, Pawitan Y, Soong R, Cooper DN, $\mathrm{Ku} C S$ : Human genetics and genomics a decade after the release of the draft sequence of the human genome. Hum Genomics 2011;5: 577-622.

48 Liu L, Li Y, Li S, Hu N, He Y, Pong R, Lin D, $\mathrm{Lu} \mathrm{L}$, Law M: Comparison of next-generation sequencing systems. J Biomed Biotechnol 2012;2012:251364

49 Bleidorn C: Third generation sequencing: technology and its potential impact on evolutionary biodiversity research. Syst Biodivers 2016;14:1-8.

50 Rothberg JM, Leamon JH: The development and impact of 454 sequencing. Nat Biotechnol 2008;26:1117-1124.

51 Chi KR: The year of sequencing. Nat Methods 2008;5:11-14.

52 Mardis ER: Next-generation DNA sequencing methods. Annu Rev Genomics Hum Genet 2008;9:387-402.

53 Mardis ER: The impact of next-generation sequencing technology on genetics. Trends Genet 2008;24:133-141.

54 Illumina: Sequencing power for every scale. 2016. http://www.illumina.com/systems/ sequencing.html.

55 Quail MA, Smith M, Coupland P, Otto TD, Harris SR, Connor TR, Bertoni A, Swerdlow $\mathrm{HP}, \mathrm{Gu} \mathrm{Y}$ : A tale of three next generation sequencing platforms: comparison of Ion Torrent, Pacific Biosciences and Illumina MiSeq sequencers. BMC Genomics 2012;13: 341.

56 Eid J, Fehr A, Gray J, et al: Real-time DNA sequencing from single polymerase molecules. Science (New York) 2009;323:133-138.

57 Lee H, Gurtowski J, Yoo S, Marcus S, McCombie WR, Schatz M: Error correction and assembly complexity of single molecule sequencing reads. bioRxiv 2014. https://doi. org/10.1101/006395. 
58 Rhoads A, Au KF: PacBio sequencing and its applications. Genomics Proteomics Bioinformatics 2015;13:278-289.

59 Feng Y, Zhang Y, Ying C, Wang D, Du C: Nanopore-based fourth-generation DNA sequencing technology. Genomics Proteomics Bioinformatics 2015;13:4-16.

60 Wang J, Moore NE, Deng YM, Eccles DA, Hall RJ: MinION nanopore sequencing of an influenza genome. Front Microbiol 2015;6:766

61 Kilianski A, Haas JL, Corriveau EJ, Liem AT, Willis KL, Kadavy DR, Rosenzweig CN, Minot SS: Bacterial and viral identification and differentiation by amplicon sequencing on the MinION nanopore sequencer. Gigascience $2015 ; 4: 1-8$.

62 Goodwin S, McPherson JD, McCombie WR: Coming of age: ten years of next-generation sequencing technologies. Nat Rev Genet 2016; 17:333-351.

63 Datta S, Budhauliya R, Das B, Chatterjee S, Vanlalhmuaka, Veer V: Next-generation sequencing in clinical virology: discovery of new viruses. World J Virol 2015;4:265-276.

64 Tringe SG, Rubin EM: Metagenomics: DNA sequencing of environmental samples. Nat Rev Genet 2005;6:805-814.

65 Daly GM, Bexfield N, Heaney J, Stubbs S, Mayer AP, Palser A, Kellam P, Drou N, Caccamo M, Tiley L, Alexander GJ, Bernal W, Heeney JL: A viral discovery methodology for clinical biopsy samples utilising massively parallel next generation sequencing. PLoS One 2011;6:e28879.

66 Hall RJ, Wang J, Todd AK, Bissielo AB, Yen S, Strydom H, Moore NE, Ren X, Huang QS, Carter PE, Peacey M: Evaluation of rapid and simple techniques for the enrichment of viruses prior to metagenomic virus discovery. J Virol Methods 2014;195:194-204.

67 Allander T, Emerson SU, Engle RE, Purcell RH, Bukh J: A virus discovery method incorporating DNase treatment and its application to the identification of two bovine parvovirus species. Proc Natl Acad Sci USA 2001;98:11609-11614.

68 He S, Wurtzel O, Singh K, Froula JL, Yilmaz S, Tringe SG, Wang Z, Chen F, Lindquist EA, Sorek R, Hugenholtz P: Validation of two ribosomal RNA removal methods for microbial metatranscriptomics. Nat Methods 2010; 7:807-812.

69 Li SK, Zhou JW, Yim AK, Leung AK, Tsui SK, Chan TF, Lau TC: Organism-specific rRNA capture system for application in next-generation sequencing. PLoS One 2013;8:e74286.

70 Dupinay T, Nguyen A, Croze C, Barbet F, Rey C, Mavingui P, Pépin M, Lachuer J, LegrasLachuer C: Next-generation sequencing of ultra-low copy samples: from clinical FFPE samples to single cell sequencing. Curr Top Virol 2012;10:63-83.

71 Lefterova MI, Suarez CJ, Banaei N, Pinsky BA: Next-generation sequencing for infectious disease diagnosis and management: a report of the association for molecular pathology. J Mol Diagn 2015;17:623-634.

72 Mertes F, Elsharawy A, Sauer S, van Helvoort JM, van der Zaag PJ, Franke A, Nilsson M, Lehrach H, Brookes AJ: Targeted enrichment of genomic DNA regions for next-generation sequencing. Brief Funct Genomics 2011;10: 374-386.

73 Jones MR, Good JM: Targeted capture in evolutionary and ecological genomics. Mol Ecol 2016;25:185-202.

74 Briese T, Kapoor A, Mishra N, Jain K, Kumar A, Jabado OJ, Lipkin WI: Virome capture sequencing enables sensitive viral diagnosis and comprehensive virome analysis. mBio 2015; 6:e01491-e01415.

75 Wylie TN, Wylie KM, Herter BN, Storch GA Enhanced virome sequencing using targeted sequence capture. Genome Res 2015;25: 1910-1920.

76 Hammoumi S, Vallaeys T, Santika A, Leleux P, Borzym E, Klopp C, Avarre JC: Targeted genomic enrichment and sequencing of CyHV-3 from carp tissues confirms low nucleotide diversity and mixed genotype infections. PeerJ 2016;4:e2516.

77 Chaudhary N, Sharma AK, Agarwal P, Gupta A, Sharma VK: 16S classifier: a tool for fast and accurate taxonomic classification of $16 \mathrm{~S}$ rRNA hypervariable regions in metagenomic datasets. PLoS One 2015;10:e0116106.

78 Mizrahi-Man O, Davenport ER, Gilad Y: Taxonomic classification of bacterial 16S rRNA genes using short sequencing reads: evaluation of effective study designs. PLoS One 2013;8:e53608

79 Sakowski EG, Munsell EV, Hyatt M, Kress W, Williamson SJ, Nasko DJ, Polson SW, Wommack KE: Ribonucleotide reductases reveal novel viral diversity and predict biological and ecological features of unknown marine viruses. Proc Natl Acad Sci USA 2014;111: 15786-15791.

80 Bidle KD: Elucidating marine virus ecology through a unified heartbeat. Proc Natl Acad Sci USA 2014;111:15606-15607.

81 Freitas TA, Li PE, Scholz MB, Chain PS: Accurate read-based metagenome characterization using a hierarchical suite of unique signatures. Nucleic Acids Res 2015;43:e69.

82 Ounit R, Wanamaker S, Close TJ, Lonardi S: CLARK: fast and accurate classification of metagenomic and genomic sequences using discriminative $k$-mers. BMC Genomics 2015; $16: 236$

83 Langmead B, Trapnell C, Pop M, Salzberg SL: Ultrafast and memory-efficient alignment of short DNA sequences to the human genome. Genome Biol 2009; 10:R25.

84 Caboche S, Audebert C, Lemoine Y, Hot D: Comparison of mapping algorithms used in high-throughput sequencing: application to Ion Torrent data. BMC Genomics 2014;15:264.

85 Lunter G, Goodson M: Stampy: a statistical algorithm for sensitive and fast mapping of Illumina sequence reads. Genome Res 2011; 21:936-939.

86 Sedlazeck FJ, Rescheneder P, von Haeseler A: NextGenMap: fast and accurate read mapping in highly polymorphic genomes. Bioinformatics (Oxford) 2013;29:2790-2791.

87 Turki T, Roshan U: MaxSSmap: a GPU program for mapping divergent short reads to genomes with the maximum scoring subsequence. BMC Genomics 2014;15:969.
88 Alavandi SV, Poornima M: Viral metagenomics: a tool for virus discovery and diversity in aquaculture. Indian J Virol 2012;23: 88-98.

89 Dolled-Filhart MP, Lee M Jr, Ou-Yang CW, Haraksingh RR, Lin JC: Computational and bioinformatics frameworks for next-generation whole exome and genome sequencing. Sci World J 2013;2013:730210.

90 Meiring TL, Salimo AT, Coetzee B, Maree HJ, Moodley J, Hitzeroth, II, Freeborough MJ, Rybicki EP, Williamson AL: Next-generation sequencing of cervical DNA detects human papillomavirus types not detected by commercial kits. Virol J 2012;9:164.

91 Thomas T, Gilbert J, Meyer F: Metagenomics - a guide from sampling to data analysis. Microb Inform Exp 2012;2:3.

92 Rampelli S, Soverini M, Turroni S, Quercia S, Biagi E, Brigidi P, Candela M: ViromeScan: a new tool for metagenomic viral community profiling. BMC Genomics 2016;17: 165.

93 Roux S, Tournayre J, Mahul A, Debroas D, Enault F: Metavir 2: new tools for viral metagenome comparison and assembled virome analysis. BMC Bioinformatics 2014;15: 76.

94 Vinithkumar NV: Marine bioinformatics. Advanced Biotech. 2006. https://www. researchgate.net/publication/265564431_ Marine_Bioinformatics.

95 Hurwitz BL, Sullivan MB: The Pacific Ocean virome (POV): a marine viral metagenomic dataset and associated protein clusters for quantitative viral ecology. PLoS One 2013; 8:e57355.

96 Ignacio-Espinoza JC, Solonenko SA, Sullivan MB: The global virome: not as big as we thought? Curr Opin Virol 2013;3:566-571.

97 Hurwitz BL, Brum JR, Sullivan MB: Depthstratified functional and taxonomic niche specialization in the "core" and "flexible" $\mathrm{Pa}$ cific Ocean virome. ISME J 2015;9:472-484.

98 Seguritan V, Alves N Jr, Arnoult M, Raymond A, Lorimer D, Burgin AB Jr, Salamon P, Segall AM: Artificial neural networks trained to detect viral and phage structural proteins. PLoS Comput Biol 2012; 8:e1002657.

99 Bailey TL, Boden M, Buske FA, Frith M, Grant CE, Clementi L, Ren J, Li WW, Noble WS: MEME SUITE: tools for motif discovery and searching. Nucleic Acids Res 2009; 37:W202-W208.

100 Mann NH, Cook A, Millard A, Bailey S, Clokie M: Marine ecosystems: bacterial photosynthesis genes in a virus. Nature 2003; 424:741.

101 Tzahor S, Man-Aharonovich D, Kirkup BC, Yogev T, Berman-Frank I, Polz MF, Beja O, Mandel-Gutfreund Y: A supervised learning approach for taxonomic classification of core-photosystem-II genes and transcripts in the marine environment. BMC Genomics 2009; 10:229

102 Miller JR, Koren S, Sutton G: Assembly algorithms for next-generation sequencing data. Genomics 2010;95:315-327. 
103 Archer J, Whiteley G, Casewell NR, Harrison RA, Wagstaff SC: VTBuilder: a tool for the assembly of multi isoform transcriptomes. BMC Bioinformatics 2014;15:389.

104 Toseland A, Moxon S, Mock T, Moulton V: Metatranscriptomes from diverse microbial communities: assessment of data reduction techniques for rigorous annotation. BMC Genomics 2014;15:901.

105 Yang X, Charlebois P, Gnerre S, Coole MG, Lennon NJ, Levin JZ, Qu J, Ryan EM, Zody MC, Henn MR: De novo assembly of highly diverse viral populations. BMC Genomics 2012;13:475.

106 Chen YC, Liu T, Yu CH, Chiang TY, Hwang CC: Effects of GC bias in next-generationsequencing data on de novo genome assembly. PLoS One 2013;8:e62856.

107 Gawad C, Koh W, Quake SR: Single-cell genome sequencing: current state of the science. Nat Rev Genet 2016;17:175-188.

108 Bankevich A, Nurk S, Antipov D, Gurevich AA, Dvorkin M, Kulikov AS, Lesin VM, Nikolenko SI, Pham S, Prjibelski AD, Pyshkin AV, Sirotkin AV, Vyahhi N, Tesler G, Alekseyev MA, Pevzner PA: SPAdes: a new genome assembly algorithm and its applications to single-cell sequencing. J Comput Biol 2012;19:455-477.

109 Chitsaz H, Yee-Greenbaum JL, Tesler G, Lombardo MJ, Dupont CL, Badger JH, Novotny $M$, Rusch DB, Fraser LJ, Gormley NA, Schulz-Trieglaff O, Smith GP, Evers DJ, Pevzner PA, Lasken RS: Efficient de novo assembly of single-cell bacterial genomes from short-read data sets. Nat Biotechnol 2011;29:915-921.

110 Peng Y, Leung HC, Yiu SM, Chin FY: IDBAUD: a de novo assembler for single-cell and metagenomic sequencing data with highly uneven depth. Bioinformatics (Oxford) 2012;28:1420-1428.

111 Lopez-Barragan MJ, Quinones M, Cui K, Lemieux J, Zhao K, Su XZ: Effect of PCR extension temperature on high-throughput sequencing. Mol Biochem Parasitol 2011;176: 64-67.

112 Van Nieuwerburgh F, Soetaert S, Podshivalova K, Ay-Lin Wang E, Schaffer L, Deforce D, Salomon DR, Head SR, Ordoukhanian P: Quantitative bias in Illumina TruSeq and a novel post amplification barcoding strategy for multiplexed DNA and small RNA deep sequencing. PLoS One 2011; 6:e26969.

113 Johnson SS, Zaikova E, Goerlitz DS, Bai Y, Tighe SW: Real-time DNA sequencing in the Antarctic dry valleys using the Oxford Nanopore Sequencer. J Biomol Tech 2017; 28:2-7.

114 Quick J, Loman NJ, Duraffour S, et al: Realtime, portable genome sequencing for Ebola surveillance. Nature 2016;530:228-232.

115 Palacios G, Lovoll M, Tengs T, Hornig M, Hutchison S, Hui J, Kongtorp RT, Savji N,
Bussetti AV, Solovyov A, Kristoffersen AB, Celone C, Street C, Trifonov V, Hirschberg DL, Rabadan R, Egholm M, Rimstad E, Lipkin WI: Heart and skeletal muscle inflammation of farmed salmon is associated with infection with a novel reovirus. PLoS One 2010;5:e11487.

116 Haugland O, Mikalsen AB, Nilsen P, Lindmo K, Thu BJ, Eliassen TM, Roos N, Rode M, Evensen O: Cardiomyopathy syndrome of atlantic salmon (Salmo salar L.) is caused by a double-stranded RNA virus of the Totiviridae family. J Virol 2011;85:52755286.

117 Lovoll M, Wiik-Nielsen J, Grove S, WiikNielsen CR, Kristoffersen AB, Faller R, Poppe T, Jung J, Pedamallu CS, Nederbragt AJ, Meyerson M, Rimstad E, Tengs T: A novel totivirus and piscine reovirus (PRV) in Atlantic salmon (Salmo salar) with cardiomyopathy syndrome (CMS). Virol J 2010;7:309.

118 Lopez-Bueno A, Mavian C, Labella AM, Castro D, Borrego JJ, Alcami A, Alejo A: Concurrence of iridovirus, polyomavirus and a unique member of a new group of fish papillomaviruses in lymphocystis disease affected gilthead seabream. J Virol 2016;90: 8768-8779.

119 Mavian C, Lopez-Bueno A, Fernandez Somalo MP, Alcami A, Alejo A: Complete genome sequence of the European sheatfish virus. J Virol 2012;86:6365-6366

120 Davison AJ, Kurobe T, Gatherer D, Cunningham C, Korf I, Fukuda H, Hedrick RP, Waltzek TB: Comparative genomics of carp herpesviruses. J Virol 2013;87:2908-2922.

121 Li W, Lee X, Weng S, He J, Dong C: Wholegenome sequence of a novel Chinese cyprinid herpesvirus 3 isolate reveals the existence of a distinct European genotype in East Asia. Vet Microbiol 2015;175:185-194.

122 Falk K, Aspehaug V, Vlasak R, Endresen C: Identification and characterization of viral structural proteins of infectious salmon anemia virus. J Virol 2004;78:3063-3071.

123 Fourrier M, Lester K, Markussen T, Falk K, Secombes CJ, McBeath A, Collet B: Dual mutation events in the haemagglutininesterase and fusion protein from an infectious salmon anaemia virus HPR0 genotype promote viral fusion and activation by an ubiquitous host protease. PLoS One 2015; 10:e0142020.

124 Markussen T, Sindre H, Jonassen CM, Tengs T, Kristoffersen AB, Ramsell J, Numanovic S, Hjortaas MJ, Christiansen DH, Dale OB, Falk K: Ultra-deep pyrosequencing of partial surface protein genes from infectious salmon anaemia virus (ISAV) suggest novel mechanisms involved in transition to virulence. PLoS One 2013;8:e81571.

125 Campbell S, Collet B, Einer-Jensen K, Secombes CJ, Snow M: Identifying potential virulence determinants in viral haemorrhagic septicaemia virus (VHSV) for rain- bow trout. Dis Aquat Organ 2009;86:205212.

126 Kim SH, Thu BJ, Skall HF, Vendramin N Evensen O: A single amino acid mutation (I1012F) of the RNA polymerase of marine viral hemorrhagic septicemia virus changes in vitro virulence to rainbow trout gill epithelial cells. J Virol 2014;88:7189-7198.

127 Schonherz AA, Lorenzen N, Guldbrandtsen B, Buitenhuis B, Einer-Jensen K: Ultra-deep sequencing of VHSV isolates contributes to understanding the role of viral quasispecies. Vet Res 2016;47:10

128 Depledge DP, Kundu S, Jensen NJ, Gray ER, Jones M, Steinberg S, Gershon A, Kinchington PR, Schmid DS, Balloux F, Nichols RA, Breuer J: Deep sequencing of viral genomes provides insight into the evolution and pathogenesis of varicella zoster virus and its vaccine in humans. Mol Biol Evol 2014;31: 397-409.

129 Depledge DP, Palser AL, Watson SJ, Lai IY, Gray ER, Grant P, Kanda RK, Leproust E, Kellam P, Breuer J: Specific capture and whole-genome sequencing of viruses from clinical samples. PLoS One 2011;6:e27805.

130 Lui VW, Yau DM, Cheung CS, Wong SC, Chan AK, Zhou Q, Wong EY, Lau CP, Lam EK, Hui EP, Hong B, Hui CW, Chan AS, Ng PK, Ng YK, Lo KW, Tsang CM, Tsui SK, Tsao SW, Chan AT: FGF8b oncogene mediates proliferation and invasion of EpsteinBarr virus-associated nasopharyngeal carcinoma cells: implication for viral-mediated FGF8b upregulation. Oncogene 2011;30: 1518-1530.

131 Donohoe OH, Henshilwood K, Way K, Hakimjavadi R, Stone DM, Walls D: Identification and characterization of cyprinid herpesvirus-3 (CyHV-3) encoded microRNAs. PLoS One 2015; 10:e0125434.

132 Kim Y, Aw TG, Teal TK, Rose JB: Metagenomic investigation of viral communities in ballast water. Environ Sci Technol 2015;49: 8396-8407.

133 Byrd AL, Segre JA: Infectious disease: adapting Koch's postulates. Science (New York) 2016;351:224-226.

134 Rivers TM: Viruses and Koch's postulates. J Bacteriol 1937;33:1-12.

135 Fredricks DN, Relman DA: Sequence-based identification of microbial pathogens: a reconsideration of Koch's postulates. Clin Microbiol Rev 1996;9:18-33.

136 Lipkin WI: The changing face of pathogen discovery and surveillance. Nat Rev Microbiol 2013;11:133-141.

137 Berthet N, Dickinson P, Filliol I, Reinhardt AK, Batejat C, Vallaeys T, Kong KA, Davies C, Lee W, Zhang S, Turpaz Y, Heym B, Coralie G, Dacheux L, Burguière AM, Bourhy H, Old IG, Manuguerra JC, Cole ST, Kennedy GC: Massively parallel pathogen identification using high-density microarrays. Microb Biotechnol 2008;1:79-86. 